\title{
revista portuguesa de pedagogia
}

\section{Cyberbullying e ambiente escolar: um estudo exploratório e colaborativo entre a escola e a universidade}
Autor(es):
Freire, Isabel; Alves, Maria Manuela; Breia, Ana Paula; Conceição, Diana; Fragoso, Lenia

Publicado por: Imprensa da Universidade de Coimbra

URL persistente:

URI:http://hdl.handle.net/10316.2/34424

DOI:

DOI:http://dx.doi.org/10.14195/1647-8614_47-2_3

Accessed : $\quad$ 26-Apr-2023 06:33:17

A navegação consulta e descarregamento dos títulos inseridos nas Bibliotecas Digitais UC Digitalis, UC Pombalina e UC Impactum, pressupõem a aceitação plena e sem reservas dos Termos e Condições de Uso destas Bibliotecas Digitais, disponíveis em https://digitalis.uc.pt/pt-pt/termos.

Conforme exposto nos referidos Termos e Condições de Uso, o descarregamento de títulos de acesso restrito requer uma licença válida de autorização devendo o utilizador aceder ao(s) documento(s) a partir de um endereço de IP da instituição detentora da supramencionada licença.

Ao utilizador é apenas permitido o descarregamento para uso pessoal, pelo que o emprego do(s) título(s) descarregado(s) para outro fim, designadamente comercial, carece de autorização do respetivo autor ou editor da obra.

Na medida em que todas as obras da UC Digitalis se encontram protegidas pelo Código do Direito de Autor e Direitos Conexos e demais legislação aplicável, toda a cópia, parcial ou total, deste documento, nos casos em que é legalmente admitida, deverá conter ou fazer-se acompanhar por este aviso. 

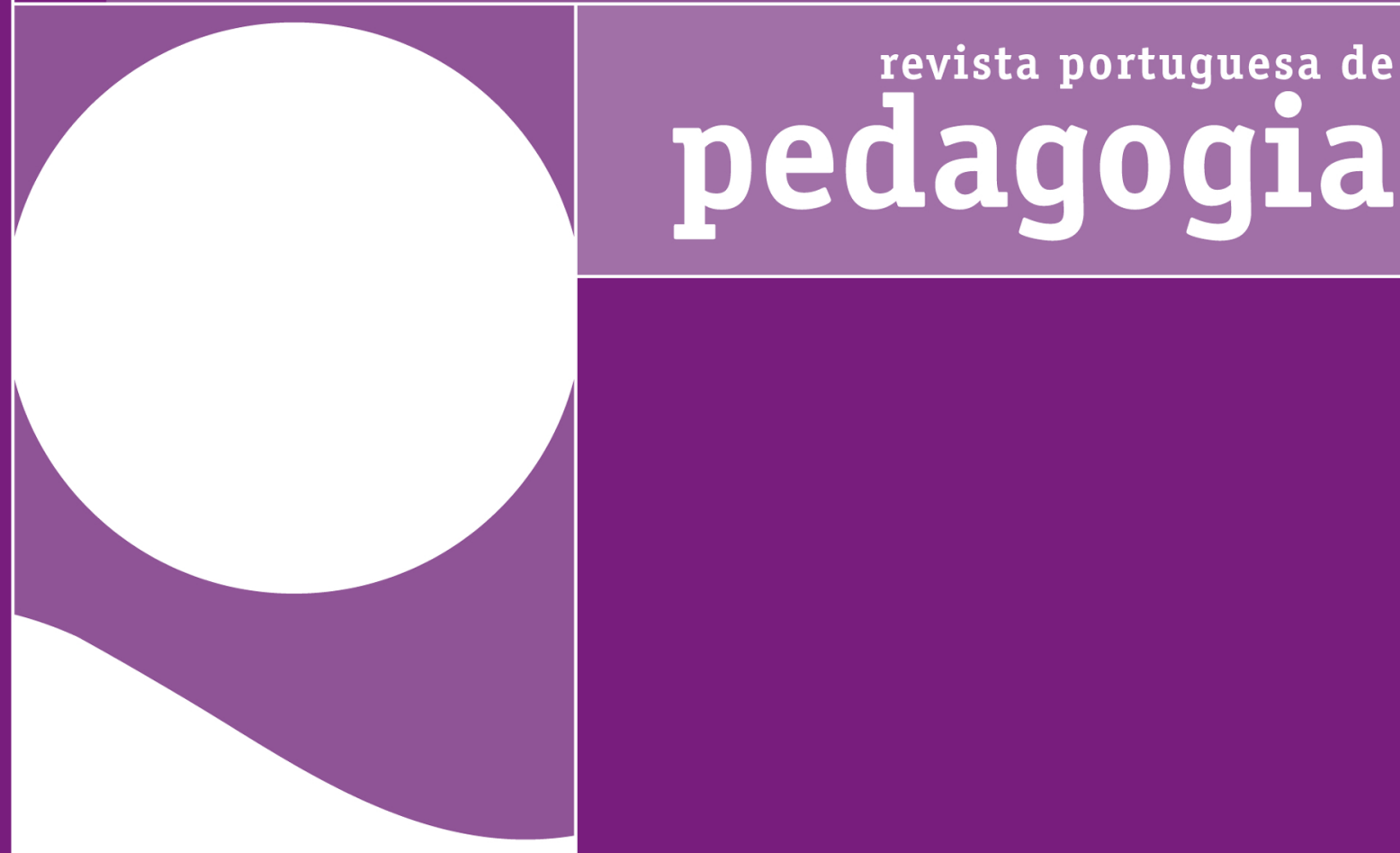


\title{
Cyberbullying e Ambiente Escolar: Um Estudo Exploratório e Colaborativo entre a Escola e a Universidade
}

\author{
Isabel Freire', Maria Manuela Alves², Ana Paula Breia ${ }^{3}$, Diana Conceição ${ }^{4}$ \\ e Lenia Fragoso ${ }^{5}$
}

\begin{abstract}
Resumo
Neste texto apresenta-se um estudo sobre a temática do cyberbullying, realizado com os alunos do 8 o ano de escolaridade de uma escola privada. Faz-se uma descrição do fenómeno em estudo naquela realidade educativa e evidenciam-se algumas relações com o ambiente relacional e social da escola, com base na análise de dados recolhidos através de um questionário de respostas fechadas e abertas. Observou-se que, nesta amostra de alunos, o contacto com o cyberbullying apresenta uma incidência relativamente alta, e que este fenómeno se liga às relações escolares entre pares, parecendo que a intimidação presencial é transposta para o ciberespaço. Os resultados da análise revelam ainda que uma importante parte dos jovens são observadores do fenómeno. Parecem existir alguns indícios de associação entre a incidência relativamente alta de cyberbullying e o ambiente sociorelacional da escola, onde alguns alunos se sentem discriminados.
\end{abstract}

Palavras-chave: cyberbullying; ambiente escolar; discriminação; colaboração escola-universidade

\section{Introdução}

As oportunidades, cada vez mais alargadas, de participação no ciberespaço fomentam uma cibercultura, onde são constantes a possibilidade de comunicar sem barreiras e a partilha de informações e bens culturais. Coloca-se então um verdadeiro

1 Instituto de Educação da Universidade de Lisboa. Email: isafrei@ie.ul.pt

2 Mestranda do Instituto de Educação da Universidade de Lisboa. Email: mmfa@campus.ul.pt

3 Mestranda do Instituto de Educação da Universidade de Lisboa. Email: pvbreia@gmail.com

4 Mestranda do Instituto de Educação da Universidade de Lisboa. Email: diaconceicao@gmail.com

5 Mestranda do Instituto de Educação da Universidade de Lisboa. Email: leny_fragoso@hotmail.com 
imperativo a todos os educadores: estar alerta em relação às potencialidades dos meios de comunicação associados às novas tecnologias, maximizando-as, e também aos riscos do seu uso.

As novas Tecnologias de Informação e Comunicação (TIC) fomentam a criação de redes sociais, geradoras de novas e múltiplas interações entre indivíduos, que vão além dos espaços físicos confinados, nomeadamente o espaço escolar e o espaço do lar. Rompem com a diferenciação de espaços de convívio, alargando-os e integrando-os, mas também aumentam tremendamente os espaços que os jovens e as crianças sentem como ameaçadores. Os múltiplos perigos a que estão sujeitos no uso destes espaços estão caracterizados (Trolley \& Hanel, 2010).

No presente texto pretendemos tratar esta dimensão da vida das novas gerações, na expressão hoje conhecida por cyberbullying e explorar algumas articulações entre o fenómeno e o ambiente escolar.

Tem sido produzida muita investigação sobre o tema do bullying, desde os estudos pioneiros de Olweus, divulgados na década de setenta do século passado (e.g., Olweus, 2000; Smith \& Sharp, 1998;) Por isso, podemos afirmar que existe um conhecimento relevante sobre esta temática, nas vertentes individual, grupal e societal. Também nas últimas décadas do século XX surgiram investigações que contribuiram para a compreensão do fenómeno numa perspetiva organizacional, ou seja, estudos que ajudaram a perceber ligações entre o fenómeno bullying e o ambiente escolar (e.g., Jones \& Jones, 1997; Smith \& Sharp, 1998). A investigação demonstra que a existência de um ethos escolar, que se traduz na partilha de atitudes, valores e práticas por parte dos membros do coletivo, está associada a uma menor prevalência quer do bullying, quer da indisciplina em geral (Freire, 2011; Freire \& Amado, 2010). Não se trata de existirem determinadas especificidades que fazem a diferença, são as escolas no seu todo que fazem essa diferença, pelo ambiente que nelas "se respira" de partilha, de consistência entre os professores, a direção e outros colaboradores, bem como entre os alunos. Embora nos manuais para educadores se encontrem com frequência muitas recomendações sobre o tema, escasseiam na literatura científica abordagens à relação entre o ambiente escolar e a expressão mais recente e perturbante do bullying - o cyberbullying.

Esta constatação foi o desafio que impulsionou a realização do estudo exploratório que aqui se apresenta, com o qual se pretende não só contribuir para a caraterização do fenómeno, como pôr em evidência a sua ligação com alguns aspetos do ambiente escolar. Tratando-se de um estudo exploratório, não visa fazer qualquer tipo de generalização, já que nem os procedimentos metodológicos utilizados, nem a amostra o permitem. 
O trabalho de pesquisa que se apresenta é um subestudo, de um estudo piloto, que fez parte da primeira fase do projeto «Cyberbullying - Um diagnóstico da situação em Portugal» ${ }^{6}$.

A pesquisa empírica foi realizada junto dos alunos do $8^{\circ}$ ano de escolaridade de uma escola privada da cidade de Lisboa. Surgiu na sequência de um pedido da própria escola à equipa de investigação, com vista ao diagóstico do problema nas turmas do 8 o ano (presumia-se que era com estes alunos que o problema tomava maiores proporções). O pedido da direção da escola visava a realização do diagnóstico e a futura implementação de medidas preventivas e de intervenção face aos problemas detetados. Pretendeu-se, assim, conciliar os interesses educativos da institutição que nos fez o pedido, com os interesses científicos do projeto, através da colaboração entre a universidade e a escola em causa. Assim, este estudo exploratório visou contribuir para a discussão das seguintes questões: i. Qual a incidência do cyberbullying em alunos do 8ªno do Ensino Básico daquela escola privada?; ii. Quais as estratégias de combate ao cyberbullying valorizadas pelos alunos deste nível de ensino?; iii. Quais os sentimentos e emoções experimentados pelos adolescentes envolvidos no fenómeno?; iv. Como é que estes jovens perspetivam o ambiente relacional e social da escola que frequentam?; v. Será que existe alguma relação entre a prevalência do cyberbullying e o ambiente relacional sentido na escola?

Com estas últimas questões pretendia-se analisar a relação entre o cyberbullying e o ambiente escolar, e também recolher informação que pudesse vir a contribuir para a construção do questionário definitivo do projeto ${ }^{7}$. Nesse sentido, incluímos no questionário aplicado neste estudo exploratório algumas questões de resposta aberta sobre o ambiente relacional e social da escola. Sabemos que o conceito de ambiente escolar é complexo e multidimensional e não tivemos a pretensão de o estudar de forma exaustiva, pois que não dispunhamos de abertura por parte da escola, nem de meios para o fazer, nem era esse o objetivo. Assim, considerámos apenas a dimensão relacional e social (aspeto pertinente para a escola que nos fez o pedido), a partir da recolha de informação relativa aos sentimentos experimentados face à escola pelos jovens alunos participantes.

6 Este projeto, que integra investigadores das Universidades de Coimbra e de Lisboa e tem como investigador responsável João Amado, é financiado no âmbito do Programa Operacional Temático Fatores de Competitividade (COMPETE) e comparticipado pelo Fundo Comunitário Europeu FEDER (Ref. PTDC/ CPE-CED/108563/2008).

7 Este estudo exploratório decorreu no final da primeira fase do projeto «Cyberbullying - Um diagnóstico da situação em Portugal». Na primeira fase foi aplicado um questionário, em grande parte constituído por perguntas de resposta aberta, que teve como objetivo recolher dados, junto de alunos dos 20 e $3 \circ$ ciclos do ensino básico e do ensino secundário, em diversas escolas das zonas de Lisboa e de Coimbra, cuja análise veio a fornecer indicadores para a construção do questionário definitivo, posteriormente aplicado a nível nacional. 


\section{Bullying e cyberbullying: as duas faces da mesma moeda}

Importa definir o conceito de bullying para se compreender as mutações e transfigurações que as novas redes sociais fomentam, surgindo assim o vocábulo cyberbullying (Amado, Matos, Pessoa, \& Jäger, 2009). O bullying reporta-se à agressão, ameaça ou outra qualquer forma de intimidação, premeditadas e repetidas, entre pessoas com diferentes posições de poder numa determinada relação social, presentes num mesmo tempo e espaço. O novo conceito (cyberbullying) apresenta características distintas: ultrapassa o horizonte do espaço e do tempo e assenta em fontes de poder que se baseiam no manuseamento das novas tecnologias, que alargam o poder pessoal de quem intimida e a vulnerabilidade de quem é vítima. Estas características estão associadas à dificuldade de, por um lado, identificar o agressor e, por outro, definir o momento e o local da ofensa, dificultando a delimitação do campo de prevenção e intervenção face a este fenómeno. A associação direta do cyberbullying às TIC justifica a enorme facilidade da sua divulgação e a sua expansão junto de um universo de pessoas muito maior do que o bullying tradicional, e num tempo indeterminado.

Dos estudos portugueses sobre esta temática, destacamos o de Pinheiro (2009) para além do acima citado trabalho de Amado et al. (2009), por serem pioneiros da investigação do tema. Pinheiro (2009) sistematiza três fases de desenvolvimento do fenómeno do cyberbullying, caracterizadas de acordo com os meios e as formas de divulgação utilizados. A primeira fase designada de pré-cyberbullying (fotocopiadora e telefone fixo-imagens, textos falsos e chamadas anónimas); a segunda de cyberbullying propriamente dito (telemóveis, de 1a e 2ª geração, com mensagens de texto e com fotografias, e Internet); por fim, o bullying digital, como reflexo do aparecimento das consequências do uso da Internet (Internet e telemóveis de 3a geração com fotografias e filmes e a emergência da câmara fotográfica digital).

Nos últimos três anos, alguns trabalhos académicos têm estudado as perspetivas de diferentes protagonistas (crianças, jovens, adultos) acerca do cyberbullying, abordando-o em diferentes campos, seja no ensino básico e secundário (Campos, 2009; Pereira, 2011), seja no ensino universitário (Souza, 2011) ou mesmo junto dos meios de comunicação social (Cruz, 2011).

Um dos aspetos importantes do estudo desta problemática é o reconhecimento do fenómeno nas suas diferentes facetas. O tipo de ameaça varia em função dos meios utilizados e da sua própria evolução (desde SMS, MMS, telefone/telemóvel, correio eletrónico, salas de conversação, mensagens instantâneas, sítios da Web, etc.). O cyberbullying apresenta ainda diferentes tipos de manifestação em função do comportamento agressivo, que Willard (2005) categorizou do seguinte modo: 
- flaming - mensagens insultuosas, muito perturbadoras, acerca de uma pessoa, enviadas para um grupo online, ou para a própria pessoa, através de e-mail ou outros meios;

- assédio online (online harassment) - envio repetitivo de mensagens ofensivas, via e-mail ou através de outros mecanismos de envio de mensagens de texto;

- dissimulação - fazer passar-se por uma outra pessoa e deixá-la ficar mal;

- $\quad$ outing - enviar ou publicar informação privada, embaraçosa ou sensível sobre outra pessoa;

- denigração/humilhação - envio de revelações falsas, lesivas e cruéis sobre certa pessoa para outras, ou publicação desse material online;

- exclusão - excluir cruelmente alguém de um grupo online;

- perseguição no ciberespaço (cyberstalking) - assédio, incluindo ameaças de danos ou intimidação.

Os motivos que levam as crianças e os jovens a envolverem-se em situações de bullying e de cyberbullying também têm sido objeto de atenção. Salientam-se causas de natureza individual (e.g., falta de empatia; baixa auto-estima; falta de autocontrolo; perturbações da saúde mental) (e.g., Campbell, Slee, Spears, Butler, $\&$ Kift, 2013) e causas ligadas à familia e aos ambientes sociais (e.g., falta de supervisão ou supervisão excessiva, maus tratos) (e.g., Fanti, Demetriou, \& Hawa, 2012). A supervisão excessiva parece estar mais ligada às crianças e jovens vítimas, enquanto a falta dela e os maus tratos estão mais ligados às crianças e jovens agressores (e.g., Olweus, 2000; Scwartz, Dodge, Petti, \& Bates, 1997). Porém, a reversibilidade de papéis que parece existir no cyberbullying com frequência torna inconsistente este tipo de leituras. O que mais importa é que os educadores estejam atentos a estas fontes de dificuldade no desenvolvimento das crianças e dos jovens, no sentido de focarem a sua atenção não só nos fatores de risco, mas preferencialmente nos protetores, de modo a que se garantam as melhores condições para o seu desenvolvimento harmonioso.

Também o ambiente escolar pode favorecer ou prevenir o aparecimento quer do bullying, quer do cyberbullying, nomeadamente através dos cuidados com a clarificação de regras quanto ao uso das novas tecnologias da comunicação e os incentivos a práticas saudáveis de convivência (Ybarra, Diener-West, \& Leaf, 2007).

As estratégias de prevenção e de reação ao fenómeno também têm vindo a ser consideradas na investigação e na ação educativa, destacando-se as estratégias individuais das crianças ou dos jovens envolvidos, as estratégias dos pais, as dos professores e das escolas e autoridades legais. 


\section{Prevenção e combate ao cyberbullying}

Pais e escolas confrontam-se com uma situação nova e, muitas vezes, sentem a falta de (in)formação para intervir com eficácia preventiva e educativa. Tal situação leva a que, por vezes, se sintam tentados a pensar que o combate ao cyberbullying poderá passar pelo controlo absoluto ou total proibição do acesso às TIC. Porém, estas são uma fonte de informação útil ao desenvolvimento das capacidades dos jovens. Daí que esta opção não seja natural nem aconselhável na educação. Privar os jovens e as crianças do acesso às TIC é privá-los do acesso ao conhecimento e aos relacionamentos interpessoais fantásticos que elas permitem.

Sendo assim, como se poderá, então, prevenir e combater o cyberbullying? A resposta não é direta nem óbvia, contudo a investigação aponta algumas linhas de ação.

\section{Papel da escola}

É nas escolas que, normalmente, se dá início ao cyberbullying através do uso da Internet nas salas de computadores (Willard, 2007), através do uso abusivo de telemóveis ou outros equipamentos pessoais. Por outro lado, a investigação revela a frequente ligação entre situações de bullying presencial, que se desencadeiam na escola, e de cyberbullying (Hinduja, \& Patchin, 2009). Por isso, a escola tem a responsabilidade de garantir um ambiente seguro, com suporte emocional, baseado no respeito por todos, que incentive a aprendizagem, promova a autoestima e onde todos os alunos se sintam protegidos dos vários tipos de bullying.

Um dos aspetos centrais da prevenção de todas as formas de bullying é o diagnóstico ${ }^{8}$, de modo a avaliar a prevalência do fenómeno (através de inquéritos e de outros procedimentos) e o seu impacto no ambiente educativo. O sucesso de todo o trabalho que se segue, e também desta etapa de diagnóstico, está ligado à capacidade de envolver os diferentes agentes do processo educativo (docentes e não-docentes, psicólogos, coordenadores técnicos, órgãos de gestão, pais, alunos, autoridades locais), de forma a que se crie um sentido de comunidade que possa contribuir para a construção de um ethos de escola promotor do respeito mútuo e do bem estar de todos. Partindo dos resultados da avaliação diagnóstica, é fundamental que a escola defina um conjunto de ações integradas que envolvam todos os intervenientes no processo de combate ao bullying e cyberbullying. Propõe-se um investimento na educação e na formação, dando formação aos educadores para que possam, futuramente, elucidar os alunos, integrando programas de anti-bullying e anti-cyberbullying no

8 Aspeto amplamente salientado desde os trabalhos pioneiros de Olweus (2000). 
currículo educativo. Junto dos pais, incentivar a sua participação ativa, promovendo conferências e reuniões, bem como workshops. O projeto europeu, CyberTraining: A research-based training manual on cyberbullying, no qual colaborou uma equipa de investigadores portugueses, criou um manual de formação para formadores baseado na investigação e na prática, publicado online, em várias línguas (Jäger, 2010; Pessoa, Matos, Amado, \& Jäger, 2011). A disseminação, junto dos alunos, da sensibilização e da formação no sentido de os tornar mais conscientes do fenómeno e com mais poder para enfrentar as situações de que possam ser vítimas, é uma etapa muito relevante do processo. Paralelamente a estas ações, que poderemos considerar de prevenção primária, é preciso definir formas de prevenção secundária, ou de intervenção precoce face a situações que venham a ocorrer (Amado \& Freire, 2009); definir e aplicar regras efetivas, definir medidas disciplinares em caso de desrespeito pelas regras, que podem incluir a explicitação de uma ação muito determinada de proibição de comportamentos violentos (quando tal se justifique). Também a criação de dispositivos de mediação escolar é uma forma de mobilizar a participação dos estudantes na resolução dos seus próprios problemas. A expansão de um "espírito mediador" numa escola concorre para a prevenção de todo o tipo de violência, ajuda a desenvolver o sentido de cidadania e a construir uma visão positiva e transformadora do conflito (Freire, 2010). Outras estratégias, como forma de prevenir e responder ao cyberbullying, poderão passar por: i. instalação de software de monitorização e controlo nos computadores utilizados pelos alunos, bloqueando o acesso a determinados sites ou acedendo ao histórico da conta e promovendo a monitorização por alunos mais experientes ${ }^{9}$; ii.informação dos servidores dos recursos online (como Facebook, Twiter, Tumbler ou MySpace) e o cancelamento das contas, visto que estes têm regras específicas anti-bullying; iii. criação de meios para denúncia anónima através da existência de uma caixa colocada num local, ou pela estruturação de um sistema de e-mail; iv. designação e preparação de membros da comunidade educativa que trabalhem diretamente com os alunos para serem os seus "confidentes" como forma de os educandos se sentirem acolhidos e compreendidos ao procurarem ajuda (Hinduja \& Patchin, 2009). Face às situações de agressão específicas é indispensável a avaliação, para a definição de uma resposta adequada, documentar e preservar as provas, perceber os relacionamentos e problemas entre os participantes, questionar se o(s) agressor(es) pode $(\mathrm{m})$ ser uma ameaça para os outros e/ou para si mesmo(s), analisar a situação vítima-agressor(es), procurando

9 Hinduja e Patchin (2009) sublinham que a monitorização por alunos mais experientes pode ser uma estratégia eficaz, pois os jovens tendem a ouvir os seus pares ou jovens mais velhos com maior atenção do que os adultos. 
perceber causas, motivos e justificações para tal comportamento por parte do(s) agressor(es) e da vítima, promover ações de apoio e acompanhamento da vítima e também do agressor. Casos específicos com reiterado comportamento violento exigem respostas educativas e, eventualmente, também de acompanhamento psicológico, em articulação com os pais.

\section{Papel dos pais}

O papel dos pais no combate ao cyberbullying, sendo diferente do da escola, é complementar e deve ser baseado no mesmo princípio: o da Educação.

Deste modo, é fundamental que os pais invistam numa relação baseada na confiança e no diálogo e que estejam presentes no processo de aprendizagem dos filhos quer no que respeita às relações que estes estabelecem com os outros, quer no seu contacto com as TIC (Fanti, Demetriou, \& Hawa, 2012; Hinduja \& Patchin, 2013). Na infância é importante que os pais acompanhem os filhos na exploração das TIC, que "naveguem" com eles na Internet, que conheçam os seus interesses e os ajudem a distinguir os benefícios dos perigos desta. O uso dos equipamentos, designadamente do computador, em espaços coletivos da casa é um fator muito dissuasor de comportamentos desadequados por parte dos filhos adolescentes ou crianças. Em complemento, propõe-se a instalação de softwares de monitorização e controlo, explicando-Ihes que estes ajudá-los-ão a protegerem-se contra os perigos do uso da Internet. Perante uma situação de cyberbullying, é fundamental que os pais assumam uma atitude proativa, quer nas situações em que o filho é a vítima, quer naquelas em que é o agressor. Esta atitude dos pais face ao uso das TIC não pode desligar-se da ação educativa em geral, ou seja, da criação de uma efetiva comunicação entre pais e filhos e de relações de confiança mútua.

\section{Papel dos pares}

É importante que, desde muito cedo, as crianças sejam alertadas para a necessidade de protegerem a sua informação pessoal, não a partilhando e utilizando passwords personalizadas, e não divulgadas, nem mesmo a amigos próximos, para acesso a contas individuais online.

No que respeita à resposta perante uma situação de agressão vivida ou presenciada, a vítima deverá: "ignorar / bloquear mensagens; não responder ao agressor; guardar todas as evidências da agressão; falar com um adulto em quem confie" (Hinduja \& Patchin, 2009, p. 177). 
Também os observadores, de modo particular os jovem observadores, acreditando que podem ajudar, têm a responsabilidade de:

registar o que vê e quando; não encorajar o comportamento; não reenviar mensagens desadequadas; não rir de piadas desapropriadas; não co-agir só para se sentir integrado; defender a vítima; denunciar a agressão, mesmo que anonimamente, a um adulto. (Hinduja \& Patchin, 2009, p. 175)

\section{Papel dos agentes da lei}

O contacto com a polícia local ou com programas nacionais de prevenção da violência na escola, como são em Portugal os Programas SeguraNet ou Escola Segura, é muito importante tanto nas ações de prevenção primária e de sensibilização, como na implementação de programas de combate ao bullying e ao cyberbullying.

Os agentes da lei, em articulação com os órgãos de gestão e os educadores, têm a responsabilidade de explicar o processo de investigação de comportamentos online inapropriados e esclarecer os jovens e crianças sobre as consequências legais destes comportamentos. Em Portugal não existe legislação direta sobre o cyberbullying, mas a maioria dos atos de cyberbullying pode ficar sobre a alçada de outro tipo de legislação, relativa, por exemplo, ao cibercrime (Lei do Cibercrime - Lei n.ำ 109/2009, de 15 de setembro).

\section{Método}

\section{A escola ${ }^{10}$ e os sujeitos participantes no estudo}

A delicadeza do tema em estudo condiciona muitas vezes a escolha das organizações escolares a que podemos aceder para o realizar. Neste caso, a escolha revelou-se profícua, visto que a opção pelo estudo e aprofundamento do conhecimento sobre cyberbullying veio ao encontro do contexto específico de um estabelecimento de ensino onde algumas manifestações do fenómeno ocorreram e onde existia um clima favorável ao diagnóstico da situação. Trata-se de uma escola privada, com ensino básico e secundário, frequentada por alunos de diversas nacionalidades, dos estratos socioeconómicos médio e médio/alto.

10 Por razões de compromisso com a manutenção do anonimato da escola onde o estudo foi realizado, não se faz uma caraterização mais detalhada da mesma. 
Face à problemática e aos objetivos científicos e educativos, o estudo foi realizado com todas as turmas do 8 ano, a partir da aplicação de um questionário, ao qual responderam 87 adolescentes com idades compreendidas entre os 13 e os 14 anos, com uma distribuição equilibrada entre alunos do sexo masculino (44) e feminino (43).

\section{Instrumento de investigação}

Embora se trate de um estudo realizado numa única escola, não é assumido como um estudo de caso, uma vez que não traz a necessária visão holística do caso, dados os constrangimentos metodológicos do estudo. Apenas foi aplicado um questionário, construído pela equipa de investigação do projeto. Este questionário foi também aplicado nesta fase de estudo piloto a alunos dos 2ํ e 3ำ ciclos do Ensino Básico e do Ensino Secundário, noutras escolas públicas e privadas das zonas de Lisboa e Coimbra (Amado, Freire, Matos, Vieira, \& Pessoa, 2012).

Este questionário inclui quatro partes distintas, constituídas por perguntas de resposta fechada e outras, na sua maioria, de resposta aberta. No início do questionário é dada uma explicação sobre o que é o cyberbullying ${ }^{11}$, de forma a que os participantes possam responder ao questionário com base numa definição comum. Seguem-se algumas questões destinadas a caracterizar a amostra em termos sociodemográficos.

A segunda parte é constituída por conjuntos de questões que visam recolher informação sobre situações vividas/observadas pelo respondente:

No papel de vítima

- Já alguma vez foste vítima de injúrias, calúnias, difamação, perseguições por parte de alguém, através de mensagens por telemóvel, por email , num chat, no Hi5, etc? (resposta fechada: SIM ou NÃO);

Tratava-se de um colega da escola? (resposta fechada: SIM ou NÃO);

Que motivos podem ter levado a(s) pessoa(s) a fazer o que fez/fizeram? (RESPOSTA ABERTA);

Descreve o que fizeram ou disseram, onde estavas, o que sentiste e o que fizeste tu a seguir (RESPOSTA ABERTA);

\footnotetext{
11 A explicação dada no início do questionário é a seguinte: "As crianças e os jovens utilizam diariamente as novas tecnologias de comunicação e isso traz-lhes grandes vantagens, mas também existem situações em que através desses meios alguns colegas maltratam outros, com injúrias, calúnias, difamações, perseguições, através de mensagens por telemóvel, por e.mail , num chat, no Hi5, etc. Estamos a estudar este fenómeno que se chama Cyberbullying (...)".
} 
No papel de agressor

- Já alguma vez injuriaste, difamaste, caluniaste ou perseguiste alguém, através de mensagens por telemóvel ou por email, num chat, no Hi5, etc? (resposta fechada: SIM ou NÃO);

Tratava-se de um colega da escola? (resposta fechada: SIM ou NÃO);

Descreve o que fizeste ou disseste, onde estavas e que motivos te levaram a fazê-lo (RESPOSTA ABERTA);

No papel de observador de vítimas

- Conheces alguém que tenha sido vítima de injúrias, calúnias, difamação ou perseguição através de mensagens por telemóvel, por email, num chat, no Hi5, etc. ? (resposta fechada: SIM ou NÃO);

No caso de responderes SIM, o que pensas que essa pessoa sentiu? (RESPOSTA ABERTA);

Podes descrever a situação que essa pessoa viveu? (RESPOSTA ABERTA);

No papel de observador de agressores

- Conheces alguém que tenha injuriado, caluniado, difamado ou perseguido outra pessoa, através de mensagens por telemóvel, por email, num chat, no Hi5 etc? (resposta fechada: SIM ou NÃO);

No caso de responderes SIM, o que achas que leva uma pessoa a cometer esses actos? (RESPOSTA ABERTA);

Podes descrever essa situação? (RESPOSTA ABERTA).

A terceira parte do questionário é constituída apenas por perguntas de resposta aberta, a primeira das quais pretende recolher dados sobre o posicionamento crítico do jovem face ao fenómeno ("O que pensas acerca destes atos?"). As perguntas seguintes visam conhecer as opiniões dos jovens sobre as pessoas a quem se deve pedir ajuda numa situação de cyberbullying e que ajuda podem dar os colegas, os pais e os professores. Finalmente, colocam-se as questões: "Como achas que os alunos se sentem na tua escola?"; "Achas que há alunos que se sentem discriminados?"; "Como se manifesta essa discriminação?" 12.

12 A existência de eventuais relações de discriminação entre alunos era um dos problemas que preocupava os educadores e a direção da escola, daí terem sido colocadas estas questões no questionário. 
O questionário permite conhecer as perspetivas de cada sujeito no papel de vítima, de agressor e de observador (em função do tipo de envolvimento em situações de cyberbullying).

\section{Procedimento}

O questionário foi aplicado, na mesma semana, por um membro da equipa de investigação, nas salas de aula com o diretor da turma, depois de se ter solicitado permissão à direção da escola, aos professores e aos pais. Os alunos foram informados sobre o projeto e o questionário, com vista a obter um consentimento informado. Todos os alunos aceitaram colaborar respondendo ao questionário.

As respostas fechadas foram analisadas através de procedimentos simples de análise estatística descritiva (frequências absolutas e relativas). As respostas abertas foram analisadas segundo a técnica de análise de conteúdo, organizando a informação em categorias e indicadores (Bardin, 2008).

O conteúdo das descrições de situações de vitimação ${ }^{13}$ foi analisado considerando quatro eixos de análise: o tipo de agressão; o local da agressão; os sentimentos experienciados pela vítima e a reação da mesma. Para cada um destes eixos de análise de conteúdo foi construído um sistema de categorias e foram analisadas as frequências relativas de alunos em cuja descrição existiam unidades de informação que se incluiam no mesmo.

Os resultados deste processo de análise, designadamente o sistema de categorias e de indicadores que dele resultou, foram a base para a construção do questionário final do projeto «Cyberbullying - Um diagnóstico da situação em Portugal», constituído maioritariamente por perguntas de resposta fechada com itens de escolha múltipla e, ainda, por duas escalas, uma de ambiente escolar e outra de ambiente familiar.

\section{Resultados}

\section{Perspetiva dos alunos no papel de vítimas}

A maioria dos alunos inquiridos (70, ou seja, 80.5\%) considera não ter sido vítima de cyberbullying, enquanto $18.4 \%$ (16) admitem ter sido vítimas deste

13 As respostas dos alunos à questão “Descreve o que te fizeram ou disseram, onde estavas, o que sentiste e o que fizeste tu a seguir". 
tipo de agressão no ciberespaço; um aluno não responde. Em regra os alunos vitimizados conhecem o agressor, sendo que quase $70 \%$ das vítimas são colegas de escola do agressor. Cerca de $25 \%$ dizem não conhecer a identidade do autor de cyberbullying.

No que respeita aos meios utilizados, verifica-se que $50 \%$ dos jovens vitimados afirmam ter sido agredidos através do computador (31.3\% no Facebook), enquanto o telemóvel é referenciado por $43.8 \%$ dos alunos (25\% dizem ser agredidos através de SMS).

Quanto aos motivos que atribuem ao agressor de cyberbullying, ressalta um sentimento de incompreensão (22.2\% diz não compreender as razões e $16.7 \%$ não responde). Aqueles que enunciam motivações para tais comportamentos parecem sublinhar o papel dos pares. A violência é difícil de compreender, particularmente por aqueles que dela são vítimas! As categorias de análise são: reforço da imagem no grupo (16.7\%); pressão dos pares (5.5\%) e rejeição dos pares (5.5\%). Outros jovens referem-se a motivações de caráter mais pessoal como a maldade e o divertimento ( $16.7 \%$ cada).

Quanto às formas de agressão, na amostra estudada, o cyberbullying manifesta-se maioritariamente na forma de ofensa /injúria (38.9\%), seguido por difamação (22.2\%), gozo (16.7\%), ameaça (11.1\%) e discriminação (5.6\%).

Para a maior parte dos inquiridos (68.8\%) estes episódios aconteceram quando se encontravam em suas casas, enquanto os restantes $31.2 \%$ referem terem acontecido na escola.

Os sentimentos reportados são bastante dispersos. O sentimento de mal estar é o mais indicado (35.3\%), seguido pelo sentimento de indiferença (17.6\%). Muito próximo deste valor encontram-se os sentimentos de tristeza e de desilusão (11.8\%). Ortega, Paz, Mora-Merchán, Calmaestra e Vega (2009) concluíram que em casos de cyberbullying é comum um sentimento de tristeza, mas também de indiferença face ao acontecimento, provavelmente pela distância emocional proporcionada pela agressão por meio de um recurso tecnológico ou por desconhecimento da identidade do agressor. Verificaram ainda que o cyberbullying via telemóvel provoca sentimentos de maior solidão, quando comparado com o fenómeno via Internet.

As reações à situação de cyberbullying dos jovens enquanto vítimas são muito diversificadas e vão desde reações imediatas com uso de ferramentas tecnológicas (bloquear o messenger; desligar os aparelhos; apagar todas as evidências), até reações muito mais ponderadas e prolongadas no tempo, como mudar de escola. Uma parte dos alunos (21\%) assume uma atitude de indiferença, enquanto outros (21\%) afirmam ter conversado com alguém [pais e amigos (10.5\%) e professores $(10.5 \%)]$. 


\section{Perspetiva dos alunos no papel de agressores}

A grande maioria dos estudantes da amostra (89.7\%) responde não ter sido agressor de cyberbullying, enquanto 6.9\% (6 em 87) dizem sê-lo, sendo que 3.4\% não responde. Este resultado naturalmente deve merecer algumas reservas dado que, geralmente, os agressores não reconhecem o incómodo que causam às vítimas, ou então não têm consciência do mesmo.

Para os 6 jovens desta amostra que se dizem agressores, o seu alvo pode ser um colega da escola (3), ou não o ser (3).

Quanto aos meios utilizados, recorrem mais ao computador (3) comparativamente com o telemóvel (2) e um deles diz ter recorrido a ambos os meios, sendo o Facebook e o Chat os ambientes mais escolhidos para a agressão. Seguem-se as SMS e o YouTube.

Quanto às razões pelas quais intimidam, 4 dizem ter sido por vingança, e os restantes alegam ter sido por brincadeira. Outros autores também referiram estas razões para este tipo de comportamento, entre outras como falta de reconhecimento pelos pares, ânsia pelo reconhecimento da sua superioridade, procura de atenção, prazer pelo sofrimento alheio e também a retaliação (Hinduja \& Patchin, 2009; Trolley \& Hanel, 2010). Relativamente ao bullying tradicional, a diferença parece estar no autoreconhecimento de um sentimento de vingança por parte destes jovens que praticam cyberbullying, dado que a desvalorização da violência sobre o outro carateriza a leitura da situação por parte dos jovens bullies, que frequentemente argumentam tratar-se de uma brincadeira. A enorme frequência com que surge a vingança como motivo para o cyberbullying (e.g., Hinduja \& Patchin, 2009), em relação ao que se observa em estudos sobre o bullying presencial, pode exprimir a maior frequência de situações de retaliação e, portanto, a maior facilidade com que os jovens alternam o papel de vítimas e de agressores, usando as TIC, muitas vezes porque estas lhes conferem um sentimento de poder que não têm por si sós.

A agressão, segundo os sujeitos da amostra que estudámos, é feita maioritariamente a partir da casa do próprio, sendo também mencionados: local de férias, escola, biblioteca pública. Este dado, a confirmar-se noutras investigações, é muito relevante, pois sublinha a necessidade de os pais estarem atentos ao uso que os seus filhos fazem das ferramentas tecnológicas em casa.

Quanto aos sentimentos que as suas ações possam ter suscitado nos outros, de entre os jovens que mencionaram ter sido agressores, dois pensam ser a tristeza o sentimento predominante das vítimas, seguindo-se o mal estar, a sensação de exclusão ou de ser gozado/humilhado, ou a mera indiferença ao acontecimento (cada um destes sentimentos mencionados por um respondente). A leitura dos sentimentos experimentados pelas vítimas, por parte destes jovens que agridem, parece estar bastante próxima dos sentimentos que aquelas dizem experimentar, nomeadamente 
na sua convicção de que as suas ações provocam tristeza e mal estar naqueles que delas são vítimas. Tal leva, também, a perceber que o facto de estarem cientes das consequências dos seus atos não os leva a deixar de os praticar. Porém, leva-nos, simultaneamente, a persistir na hipótese de que, frequentemente, os papéis de agressor e vítima se invertem e, por isso, todos experimentam sentimentos face à vitimização, o que não os impede de retaliar.

\section{Perspetiva dos alunos no papel de observadores}

Através deste estudo, quisemos também retratar o olhar dos alunos enquanto observadores. Quando questionados sobre este ponto de vista, cerca de 58.6\% dos inquiridos admitem conhecer vítimas de cyberbullying, sendo o computador, através do Facebook, o meio tecnológico mais utilizado. Relativamente ao tipo de ação perpetrada de que têm conhecimento, relatam, com preponderância, a difamação (47.1\%), seguida da invasão da privacidade (23.5\%), o gozo e a ameaça (5.9\%, cada). A maior parte dos respondentes aponta para a criação de um grupo na rede social, para investir contra uma vítima. As motivações mais referidas para este tipo de agressão são o reforço da imagem no grupo/sentimento de superioridade (32.6\%), a vingança (23.3\%), o prazer pelo sofrimento alheio, a inveja (9.3\% cada), o insulto/humilhação (4.7\%), a infelicidade, a diferença cultural, os desentendimentos, a insegurança, o desconhecimento das razões e problemas em casa (2.3\%, cada).

Os observadores sublinham a ausência de responsabilidade e de culpa das vítimas em relação ao sucedido, apontando para a possibilidade da agressão se dever à passividade da vítima (17.6\%). Referiram, ainda, como razões ligadas à vítima, a inocência, o desconhecimento e também a atitude provocatória; e ligadas ao agressor a discriminação e a vingança.

Questionados sobre se fizeram algo para ajudar a vítima, a maior parte dos jovens observadores responde não ter feito nada (54.9\%) e 3.9\% não responderam. Estes resultados devem merecer a nossa atenção, uma vez que a maior parte dos nossos jovens são observadores frequentes de situações de violência, sob a forma de cyberbullying ou de outras, como outros estudos têm desmonstrado (e.g., Freire, Veiga Simão, \& Ferreira, 2006). Tal atitude pode ser muito negativa na sua formação, dado que se corre o risco de se habituarem a observar a violência sem se envolverem, aprendendo a distanciar-se do sofrimento dos outros e a organizar as suas vidas sem um sentido altruísta.

Os jovens que declaram ter intervindo, maioritariamente dizem simplesmente ter apoiado/ajudado (18.9\%), outros foram mais específicos dizendo terem utilizado o diálogo como forma de intervenção - conversar/falar com o agressor (16.2\%). 
Relativamente aos sentimentos que pensam que a vítima experimentou, referem com maior ênfase tristeza/mal estar (37.3\%), raiva/ódio (13,4\%) e humilhação (7.5\%).

A maior parte dos inquiridos (57.5\%) responde não ter conhecimento de pessoas que agridem os outros sob a forma de cyberbullying, enquanto $37.9 \%$ afirmam ter conhecimento de casos.

Relativamente aos meios tecnológicos usados, $78.8 \%$ dizem que o agressor recorre ao computador e apenas $27.3 \%$ ao telemóvel; o Facebook (64.9\%) é o meio de eleição para o cyberbullying, na visão dos observadores.

Quanto à intervenção do observador nestes episódios, as respostas oscilam entre o não (81.1\%) e o sim (18.9\%), inclinando-se demasiado para o não. Como noutras formas de bullying, verifica-se a predominância de uma atitude de demissão em relação ao sofrimento do outro, o que é preocupante e deve ser motivo de reflexão. O tipo de reação adotada pelos jovens observadores, que admitem tê-la, varia entre falar com o agressor (62.5\%), falar com um professor (12.5\%) e agredir o agressor (12.5\%). Estes dados poderão ter implícita a baixa expetativa destes jovens relativamente ao apoio dos professores e da escola onde estudam e também em relação aos pais.

\section{Perspetiva social e crítica}

Pretendeu-se, ainda, recolher informação que desse uma ideia do posicionamento moral dos jovens acerca deste fenómeno e também perspetivar ações valorizadas pelos jovens.

Saliente-se, desde logo, a ausência, por parte de cerca de $40 \%$ destes adolescentes do 8으. ano, de resposta à pergunta Que pensas acerca destes atos? Poderemos adivinhar que o não dito aqui possa ter um enorme significado e levar-nos a questionar a educação que estamos a dar a esta geração em termos éticos e de formação para a cidadania. Os alunos que respondem, conotam os atos de cyberbullying principalmente com uma atitude de irresponsabilidade (45.3\%), com sentimentos de crueldade (13.7\%) e de vingança (2.1\%). Uma pequena percentagem salienta a perigosidade e mesmo o caráter criminoso destes atos (1.1\%, cada).

Porém, uma parte importante destes jovens revela ter ideias claras acerca das formas mais adequadas de ação por parte das vítimas. Embora alguns revelem a convicção de que é preferível ignorar, a maior parte dos que respondem atribui muito valor à comunicação com outros acerca do assunto, à rutura com o isolamento, com o sofrimento solitário (e.g., conversar; falar com os pais; falar com o diretor de turma; falar com pessoas responsáveis e com conhecimento; falar com professores; falar com alguém). Estes dados são, ainda, reforçados pelas respostas que traduzem 
a convicção de que o apoio dos educadores e dos amigos é a estratégia de eleição: $21.9 \%$ dos participantes considera que os pais poderão ser as pessoas mais indicadas, seguindo-se os professores (21.3\%), os amigos (17.2\%), a escola em geral (9.5\%) e os psicólogos (7.7\%). De facto, as pessoas mais próximas e de confiança surgem como a primeira escolha dos alunos para os ajudarem a superar uma possível situação de cyberbullying (Hinduja \& Patchin, 2009; Trolley \& Hanel, 2010).

No Quadro 1 apresentam-se as formas de intervenção dos colegas, dos professores e dos pais que os alunos da amostra enunciam.

\section{Quadro 1}

Formas de Intervenção

\begin{tabular}{ccc}
\hline Colegas & Professores & Pais \\
\hline - apoiar/ajudar a vítima & - formar os alunos sobre o tema & - acompanhamento dos filhos \\
- falar com o agressor & - falar com a vítima & - falar com os professores \\
& - falar com os agressores & - falar com os pais do agressor \\
& - aconselhar/apoiar a vítima & - formar os filhos
\end{tabular}

Aos colegas atribuem um papel muito importante de apoio à vítima, aos pais o acompanhamento/supervisão e aos professores a formação. Não descuram o trabalho a realizar junto dos colegas que agridem, quer por parte dos pares, quer pelos professores, quer pelos pais.

\section{Ambiente relacional e sentimentos de discriminação na escola}

Como já afirmámos, o nosso estudo visou ainda compreender o modo como os alunos se sentiam nesta escola, onde coexistem jovens de diferentes nacionalidades. À questão Como achas que se sentem os alunos na tua escola? apenas $43.4 \%$ dos alunos respondem que se sentem bem, enquanto $16.8 \%$ referem a existência de sentimentos de mal estar. Outros expressaram sentimentos mais específicos, como a discriminação (9.7\%), o medo (6.2\%), sentimentos de inferioridade (5.3\%), de exclusão (1.8\%) ou de indiferença (3.5\%). Os restantes não responderam. Esta leitura é reforçada pelos resultados obtidos com as respostas à pergunta Achas que há alunos que se sentem discriminados? à qual $70.1 \%$ responderam sim e $29.9 \%$ responderam não. Os sentimentos de discriminação expressos pelos jovens inquiridos vão desde: i. sentimentos mais ligados à dimensão social das suas vidas [(e.g., sentir-se alvo de gozo e de exclusão (10.7\%); sentir-se isolado (8\%)]; ii. a sentimentos ligados à dimensão moral [(e.g., sentir-se difamado (9.3\%), ofendido (6.7\%) ou ameaçado 
(1.3\%)]; iii. até sentimentos ligados à dimensão psicofisiológica, no caso daqueles que admitem ter sentido alterações de humor (9.3\%). Cerca de $22.7 \%$ dos alunos não responderam a esta questão, o que também pode ser significativo. Quanto às razões apontadas para o sentimento de discriminação, os alunos indicaram as seguintes: ser alvo de gozo (23.5\%), ser diferente (20.6\%) e mais especificamente ser diferente culturalmente (10.3\%).

\section{Considerações finais}

Com o estudo que acabamos de apresentar pretendemos contribuir para um melhor conhecimento do fenómeno cyberbullying em Portugal. Com base nos dados recolhidos obtivemos descrições factuais de episódios marcantes para os jovens inquiridos, concluindo-se que o fenómeno do cyberbullying não lhes é indiferente. Quase 20\% dos estudantes desta escola admitiram ter sido vítimas de algum tipo de agressão no ciberespaço e, geralmente, conheciam o agressor, que na maior parte das vezes era seu colega, o que realça a importância do papel da escola na prevenção e na intervenção face a este fenómeno. O computador foi utilizado, neste caso, para difundir a injúria ou a agressão, designadamente através da criação de um grupo agressor numa rede social - o Facebook; no entanto, o telemóvel é, também, usado como meio de concretizar o cyberbullying. Este tipo de agressão suscita fortes sentimentos de mal estar e de tristeza na maior parte das vítimas, se bem que existam jovens-vítimas que revelam uma certa indiferença, que parece funcionar como estratégia para lidar com o problema. Na sua maioria, os jovens da amostra dizem-se observadores de cyberbullying, mais frequentemente de vítimas do que de agressores. A maioria dos jovens-observadores não desenvolve qualquer ação subsequente, denunciando, assim, a predominância de uma atitude de demissão face ao sofrimento do outro.

Todavia, estes estudantes revelam ter uma opinião bastante clara em relação à forma como as vítimas devem lidar com o problema. Sublinham a importância da comunicação com os outros, como forma de romper com o sofrimento solitário. Valorizam o papel dos pais e dos professores, mas também o dos colegas. Atribuem a estes últimos um papel de apoio; aos pais o de acompanhamento e supervisão e aos professores o de formação especialmente no uso das tecnologias e das relações interpessoais, e não descuram a importância da ação dos adultos/educadores junto dos jovens-agressores.

O estudo parece indiciar alguma ligação entre a prevalência do cyberbullying e o ambiente social e relacional sentido na escola. Apenas menos de metade da amostra manifestou a opinião de que os alunos se sentiam bem na escola. Alguns referiram-se 
especificamente à existência de sentimentos de mal estar e outros denunciaram a existência de sentimentos de discriminação, de medo e de inferioridade. A discriminação parece ser uma realidade com a qual convivem os alunos desta escola, que justificam pela dificuldade de convívio com as diferenças, nomeadamente as diferenças culturais em que predominam sentimentos ligados às diferentes identidades nacionais e culturais, o que aponta para a necessidade de uma educação intercultural, neste contexto educativo, como noutros com multiculturalidade significativa.

O ambiente sentido nesta escola poderá ser, de algum modo, potencialmente desencadeador de fenómenos de algum mal estar em que uma das expressões será o cyberbullying. Contudo, dado tratar-se de um estudo meramente descritivo, este tipo de interpretações carece de confirmação através de estudos de outra natureza.

Porém, os resultados obtidos no presente estudo indiciam que o ambiente escolar (nomeadamente as relações entre pares) pode desempenhar um papel relevante nas situações de vitimização vividas no ciberespaço, o que vem ao encontro dos resultados também encontrados por Willard (2007), que afirma que é nas escolas que o fenómeno do cyberbullying germina. Apesar da proliferação de múltiplos estudos sobre o cyberbullying, na última década, julgamos ser de grande importância o desenvolvimento de pesquisas que possam aprofundar o conhecimento sobre as ligações entre ambiente escolar, ambiente familiar e este fenómeno.

Para concluir, diremos, ainda, que cada comunidade educativa e a sociedade em geral não deverão ceder à tentação de enveredar pela sobrevalização, nem tão pouco subvalorizar o fenómeno do cyberbullying. Como referiram os alunos questionados, tanto professores como pais deverão estar atentos à emergência de comportamentos atípicos, designadamente as mudanças de humor; o isolamento; a tristeza; a alteração de rotinas (tais como evitar usar o computador e/ou atender/visualizar telemóvel, meios mais usados pelos agressores). Todos os agentes educativos devem estar conscientes das consequências mais comuns para as vítimas, das quais se salientam os prejuízos na socialização e a baixa autoestima. Há ainda os prejuízos na aprendizagem. Regista-se uma quebra na atenção da criança/do jovem, frequentemente o absentismo às aulas, bem como o impacto sobre a saúde física e emocional (Maidel, 2009). É igualmente importante que a atenção e o cuidado dos educadores sejam focados naqueles que são sistematicamente agressores, pois que o impacto desta situação no seu desenvolvimento é igualmente muito nefasto.

A colaboração entre escolas e universidades é uma questão muito relevante na abordagem aos problemas educativos. Pensamos que este estudo é um exemplo de integração da pesquisa científica nas suas vertentes fundamental e aplicada. Os seus resultados foram devolvidos à escola, que os integrou no seu plano de ação e de formação. 


\section{Referências bibliográficas}

Amado, J. S., \& Freire, I. P. (2009). A(s) indisciplina(s) na escola. Compreender para prevenir. Coimbra: Almedina.

Amado, J., Freire, I., Matos, A., Vieira, C., \& Pessoa, T. (2012). O cyberbullying e a escola. Uma análise da situação em Portugal. Atas do III Colóquio Luso-Brasileiro de Sociologia da Educação. Problemas contemporâneos da educação no Brasil e em Portugal -desafios à pesquisa, Rio de Janeiro.

Amado, J., Matos, A., Pessoa, T., \& Jäger, T. (2009). Cyberbullying: Um desafio à investigação e à formação. Revista Interacções, 5(13), 301-326.

Bardin, L. (2008). Análise de Conteúdo. Lisboa: Edições 70.

Campbell, M. A., Slee, P. T., Spears, B., Butler, D., \& Kift, S. (2013). Do cyberbullies suffer too? Cyberbulies' perceptions of the harm they cause to others and to their own mental health. School Psychology International, 34(6), 613-629. doi: 10.1177/0143034313479698

Campos, M. (2009). Cyberbullying. Natureza e ocorrência em contexto português. Lisboa: Instituto Universitário de Lisboa.

Cruz, A. (2011). O Cyberbullying no contexto português. (Tese de Mestrado, Universidade Nova de Lisboa). Consultado em http://www.fcsh.unl.pt/eukidsonline/docs/ disserta\%C3\%A7ao\%20mestrado\%20cyberbullying.pdf

Fanti, K., Demetriou, A., \& Hawa, V. (2012). A longitudinal study of cyberbullying: Examining risk and protective factors. European Journal of Developmental Psychology. 9 (2), 168-181.

Freire, I. (2010). Mediação em educação em Portugal. In J. A. Correia \& A. M. Silva (Orgs.), Mediação:(d)os contextos e (d)os actores (pp. 59-70). Porto: LibPsi, Colecção Ciências da Educação.

Freire, I. (2011). Disciplina e ethos de escola. In S. N. Caldeira \& F. H. Veiga (Orgs.), Intervir em situações de indisciplina, violência e conflito (pp. 175-198). Lisboa: Fim de Século - Edições.

Freire, I., \& Amado, J. (2010). Indisciplina(s) e clima relacional nas escolas. In C. A. Silva, M. G. Ribeiro, \& N. C. Crusoé (Orgs.), Desafios educacionais no cotidiano da escola (pp. 21-44). ljuí: Editora UNIJUI.

Freire, I. P., Veiga Simão, A. M., \& Ferreira, A. S. (2006). O estudo da violência entre pares no 3ำ ciclo do ensino básico - um questionário aferido para a população escolar portuguesa. Revista Portuguesa de Educação, 19(2), 157-183.

Hinduja, S., \& Patchin. J. (2009). Bullying beyond the schoolyard. Thousand Oaks: Corwin Press.

Hinduja, S., \& Patchin, J. (2013). Social influences on cyberbullying behaviours among middle and high school students. Journal of Youth Adolescence, 42, 711-722.

Jäger, T. (Ed.) (2010). Agir contra o cyberbullying - Manual de Formação. Consultado em dezembro, 2012, em http://www.cybertraining-project.org/book/pt/CT_howtouse_pt.pdf

Jones, N., \& Jones, E. B. (Eds.) (1997). Learning to behave. Curriculum and whole school management approaches to discipline. London: Kogan Page.

Maidel, S. (2009). Cyberbullying: um novo risco advindo das tecnologias digitais. Revista electrónica de investigación y docencia (reid), 113-119. Consultado em janeiro, 2011, em http://www.ujaen.es/revista/reid/revista/n2/REID2art7.pdf 
Olweus, D. (2000). Bullying at School. Oxford: Blackwell Publishers, Ltd.

Ortega, R., Paz, F., Mora-Merchán, J. A., Calmestra, J., \& Vega, E. (2009). The emotional impact on victims of traditional bullying and cyberbullying, a study of Spanish adolescents. Journal of Psychology, 217(4), 197-204.

Pereira, S. (2011). Cyberbullying: O pensamento dos Professores. (Tese de mestrado não publicada). Universidade de Coimbra, Coimbra.

Pessoa, T., Matos, A., Amado, J., \& Jäger, T. (2011). Cyberbullying - do diagnóstico de necessidades à construção de um manual de formação. Sips - Revista Interuniversitaria de Pedagogía Social, 18, 57-70.

Pinheiro, L. (2009). Cyberbullying em Portugal: Uma perspectiva sociológica (Tese de mestrado, Universidade do Minho). Consultado em https://repositorium.sdum.uminho. pt/bitstream/1822/9870/1/tese.pdf

Schwartz, D., Dodge, K. A., Petti, G. S., \& Bates, J. E. (1997). The early socialization of aggressive victims of bullying. Child Development, 68(4), 665-675.

Smith, P. K., \& Sharp S. (Eds.) (1998). School bullying. Insights and perspectives. London: Routldege.

Souza, S. (2011). Cyberbullying: Estudo exploratório sobre as perspetivas acerca do fenómeno e das estratégias de enfrentamento com jovens universitários portugueses. (Tese de mestrado não publicada). Universidade de Lisboa, Lisboa

Trolley, B., \& Hanel, C. (2010). Cyber kids, cyber bullying, cyber balance. California: Corwin.

Willard, N. (2005). Educator's guide to cyberbullying and cyberthreats. Consultado em fevereiro, 2014, em http://www.accem.org/pdf/cbcteducator.pdf

Willard, N. (2007). Cyber-safe kids, cyber-savvy teens: Helping young people learn to use the Internet safely and responsibly. San Francisco: Jossey-Bass.

Ybarra, M. L., Diener-West, M., \& Leaf, P. J. (2007). Examining the overlap in internet harassment and school bullying: implications for school intervention. Journal of Adolescent Health, 41, 42-50. 


\title{
Cyberbullying and School Environment: An Exploratory and Collaborative Study between School and University
}

\begin{abstract}
This text presents a study on the topic Cyberbullying which was carried out with pupils from the $8^{\text {th }}$ grade who attended a private school. A description of the phenomenon being studied in that context is presented and a connection to the social and relational school environment is emphasised, based on the analysis of the data collected by means of a survey comprising open-ended and closed-ended questions. Concerning this sample of pupils, it was observed that the contact with Cyberbullying shows a relative high incidence and this phenomenon is connected to school relationships among peers, seeming that face-to-face intimidation is transposed onto the cyberspace. The results of the analysis still highlight that an important number of these pupils are passive observers of this phenomenon. It therefore seems that there are some evidence of association between a relative high incidence of Cyberbullying and the socio-relational school environment, in which some pupils feel discriminated against.
\end{abstract}

Key-words: cyberbullying; school environment; discrimination; school-university collaboration

\section{Cyberbullying y Entorno de la Escuela: Un Estudio Exploratorio y de Colaboración entre la Escuela y la Universidad}

\section{Resumen}

En este trabajo se presenta un estudio sobre el tema de la intimidación cibernética, llevada a cabo con estudiantes del octavo grado en una escuela privada. Es una descripción del fenómeno en estudio en este contexto y se muestran algunas relaciones con la familia y el entorno relacional de la escuela, con base en el análisis de los datos recogidos a través de un cuestionario cerrado y abierto. Se observó que en esta muestra de estudiantes, hay una incidencia relativamente alta de contacto con cyberbullying, fenómeno que se une a las relaciones escolares entre pares. Se puede inferir que la intimidación cara a cara se transpone al ciberespacio. Los resultados del análisis muestran que una parte importante de los jóvenes son observadores del fenómeno. Parece que hay cierta evidencia de asociación entre la incidencia relativamente alta de acoso cibernético y el entorno relacional de la escuela, donde algunos estudiantes se sienten discriminados.

Palabras clave: cyberbullying; ambiente escolar; discriminación; colaboración entre la escuela y la universidad 